\title{
Awareness and Appreciation of Advertising Language
}

\author{
Trisnowati Tanto \\ trisnowatitanto@gmail.com \\ English Department, Maranatha Christian University
}

\begin{abstract}
This research focuses on advertising language in advertisement slogans of various products written in English. The grand theory used is Stylistics, which is the study of the style of language or the study of the use of distinctive linguistic expressions and how they affect the target audience. To limit the discussion, this research more specifically covered the use of rhetorical figures and doublespeak in advertising language. These language features basically have the same functions, namely the aesthetic and persuasive functions, which aim to attract the audience's attention. This research, using an explanatory research method, was done to find out people's awareness and appreciation of the outstanding use of advertising language by distributing questionnaires with Likert scale to the students and alumni of the English Department of a private university in Indonesia. Considering that in an advertisement there is also the visual aspect besides the textual aspect, the research was also done to find out whether or not there is a strong correlation between people's awareness and appreciation of the visual and textual aspects.
\end{abstract}

Keywords: advertising language, awareness, appreciation

\section{Introduction}

Advertising language has always been the main interest of many linguists for a long time since it involves a high and creative skill of language use. The language used in advertisement texts has a sole primary goal, namely to attract the potential customers. Consequently, producing a good advertisement slogan is not a simple thing to do at all; at the very least, one should pay attention to the aesthetic aspect of the language. More importantly, a copywriter has to think about how to produce a text that can sell, as stated by Judith Charles (as cited in Bly, 2005 ) that a copywriter is in fact equal to "a salesperson behind a typewriter." The persuasive atmosphere of the advertisement is built through the language.

While the high skill of a copywriter is undeniably essential, it is interesting to find out whether the readers or potential customers are aware of it, let alone appreciate it. People commonly get more easily attracted to the visual aspect of an advertisement than the textual aspect. Another phenomenon is that people may be aware that the advertisement text is quite special, but they find it difficult to be able to detect what language features contribute to the special thing about the text. Nevertheless, when they are able to do this, it can be said that they manage to appreciate the copywriter's skill.

Leigh (1994) conducts a study to find whether advertisements in magazines in the USA use figures of speech and which types of figures of speech they are. He finds out that the majority (74.3\%) of the advertisements use at least one rhetorical device.

Bizzoca (2017, p. 41) conducts a similar study of rhetorical figures found in 2768 printed advertisements, which were published 
in 2016 most circulating British magazines such as Vogue, GQ, Elle, and TopGear. She conducts a survey to find out if it is the audience that influences the advertisement or it is the opposite. However, the survey is not really successful due to the shortage of audience in the area whose mother tongue is English.

Moreover, Bizzoca (2017, p. 43) also does a translation study of how these rhetorical figures are best translated into Italian. Since the rhetorical figures function to intrigue and fascinate the customer, it is essential to transfer this into the target language. Nonetheless, many problems are likely to occur in the attempt of translating it so that the strategies used are worth analyzing.

This present study investigates people's awareness of the attractive advertising language and their appreciation of the language features used to create the attractive advertising language. There are three advertisements used as the research objects. A questionnaire with Likert scale was distributed to 150 students and alumni of the English Department of a private university in Indonesia, considering that these belong to a group of people who are supposedly quite familiar with the English language and its features. However, only 103 forms were filled in and returned, which were then further processed.

The questionnaire covers some questions concerning the respondents' awareness of the visual and textual elements in the three advertisements, whether or not they regard the visual and textual elements in the advertisements as interesting. When they think that the textual elements are interesting, they are asked to mention the particular linguistic features that contribute to the interesting slogans. Their ability to recognize the particular linguistic features demonstrates the high appreciation of the great skill of the slogan writer's use of language.

This research is a quantitative research. The data were collected in a structured way, in this case through questionnaires. Then after getting the results, the computational, statistical, and mathematical tools were used
("What is Quantitative Research", n.d.). The research used an explanatory research method, which attempts to explain by connecting different ideas and to understand the different reasons, causes and their effects.

\section{Stylistics}

The research of advertising language belongs to stylistics, which is defined as "the linguistic study of style" (Leech \& Short, 1981, p. 13). Stylistics is more specifically defined as "... a distinctive manner of expression, through whatever medium this expression is given physical shape. Along the same lines, style in language can be defined as distinctive linguistic expression" (Verdonk, 2002, p. 3).

When analyzing an advertisement, one can use a stylistic analysis to reveal not only the form and structure in the text but also those features which stand out in it. Those features "hold a promise of stylistic relevance with reader's or listener's interests or emotions" (Verdonk, 2002, p. 6).

In this research the language features focused on are the use of rhetorical figures and doublespeak as these two are the most common language features in advertisements. These features are basically used as foregrounding elements in an advertisement so that people will directly pay more attention to them and hopefully will eventually be persuaded to use or buy the products.

\section{McQuarrie and Mick's Model of Rhetorical Figures}

A rhetorical figure can be defined as "an artful deviation, relative to audience expectation, that conforms to a template independent of the specifics of the occasion where it occurs" (McQuarrie \& Mick, 1996). Furthermore, it is stated that rhetorical figures will produce a more favorable brand attitude toward the advertisement (McQuarrie \& Mick, 1996).

McQuarrie and Mick (1996) subdivide the rhetorical figure into two broad categories: schemes and tropes. Schemes are constructed by repetition (simple operation) and reversal 
(complex operation), while tropes are constructed by substitution (simple operation) and destabilization (complex operation). McQuarrie \& Mick (1996) presents the complete taxonomy of rhetorical figures in advertising, which can be seen in the following diagram:

\section{Figure 1. A Taxonomy of Rhetorical Figures in Advertising}

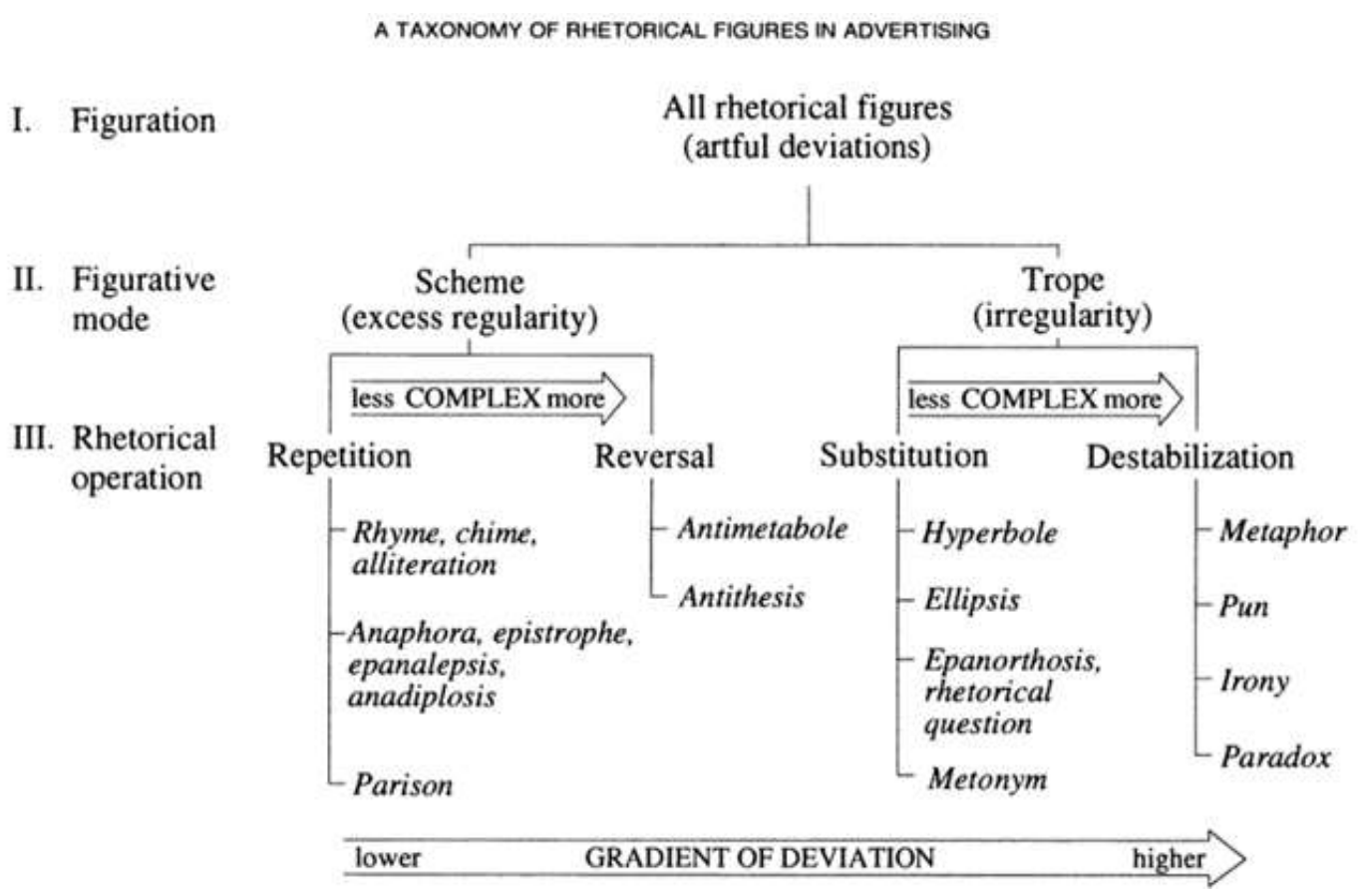

The first rhetorical operation, repetition, can be in the forms of sound or word or phrase structure repetitions. Repetition in a text can be expected to build up one's memory. For example, the slogan "Performax protects to the max" will attract the customers' attention especially because of the repeated sound /æks/ in the words Performax and max (McQuarrie \& Mick, 1996).

The second rhetorical operation, reversal, "combines elements that are mirror images of one another in an expression" (McQuarrie \& Mick, 1996). Furthermore, they add that reversal operation is like "a mirror image that repeats the original, but in reverse" (McQuarrie \& Mick, 1996). For example, the advertisement slogan "We got hot prices on cool stuff" contains the use of an antithesis, which will naturally become the main attention of the customers.

Substitution is another type of rhetorical operation that "selects an expression that requires an adjustment by the message recipient in order to grasp the intended content" (McQuarrie \& Mick, 1996). One of the figures of speech that can be found in substitution operation is hyperbole, which is very effective in advertisement as it dramatizes the selling point of the product. For example, the word whitest in the advertisement slogan "Rinso gives the whitest wash" gives a hyperbolic sense.

Destabilization is an operation that "selects an expression such that the initial context renders its meaning indeterminate" (McQuarrie \& Mick, 1996). A pun, which belongs to the destabilization operation, is defined as "the usually humorous use of a word in such a way as to suggest two or more of its meanings or the meaning of another word similar in sound" (Merriam-Webster, n.d.). Since the basic principle of wordplay is ambiguity, words belonging to homonymy or homophony, which may cause lexical ambiguity, for example, the homonymous 
word club, which can mean 'a heavy stick' and 'a social organization' (Kreidler, 1998), or the homophonous words 'bough' and 'bow', both of which are pronounced in the same way /bau/ (Wales, 1994). When they are exploited in producing humour, they become wordplay or puns. Obviously, creating a good pun requires creativity and an extraordinary skill of language (Partington, 2009).

According to Attridge, "The pun [in advertising] is the product of a context deliberately constructed to enforce an ambiguity, to render impossible the choice between meanings..." (as cited in McQuarrie \& Mick, 1996). In other words, it requires readers to make inferences in order to understand their intended meanings.

The slogan "The car in front is a Toyota" uses a genius pun. The phrase 'in front' can be understood literally, when it comes as a sticker on the rear window. However, it can also be interpreted that Toyota is in the lead in the automotive business.

All in all, it is clear that related to the two significant concepts in advertising, which are persuasion and motivation, the use of rhetorical figures can add to the persuasiveness of the advertisement message. Besides, rhetorical figures function to motivate the potential customers as well as drawing their attention to the advertisement (McQuarrie \& Mick, 1996). In other words, it is very likely that customers will find advertisement messages containing rhetorical figures more appealing (McQuarrie \& Mick, 1996).

\section{William Lutz' Doublespeak}

Doublespeak is "language that pretends to communicate but really doesn't. It is language that makes the bad seem good, the negative appear positive, the unpleasant appear attractive or at least tolerable" (Lutz, 1989, p. 1). He further states that doublespeak is used to mislead people. The practice of doublespeak can be found in many areas of life, from everyday living, politics, education, and also advertising.
In advertising doublespeak can be utilized to make something out of nothing, which is the main job of an advertiser. In other words, doublespeak in advertising has one primary job, namely to put the product to the best possible light so that customers will be attracted to buy it. Furthermore, despite having basically the intention of misleading, in the advertising world the use of doublespeak will be regarded as "creative license" (Lutz, 1989 , p. 82). There are four types of doublespeak that can be found in an advertisement, namely the rule of parity, weasel words, up to claim, and unfinished words.

Parity products are products that are basically the same, as they are made in the same way and using the same formula. Products like toothpaste, soap cosmetics, cold remedies, etc. are parity products. Since these products are in fact the same, one product cannot say it is better than the others. Hence, when a product claims something like "The best for you", it is doublespeak, and customers are supposed not to be taken in.

Weasel words are used "to appear to be making a claim for a product when in fact they are making no claim at all ... Weasel words appear to say one thing when in fact they say the opposite, or nothing at all" (Lutz, 1989, p. 85). The most often used weasel word is the word 'help', for example in the slogan "helps relieve cold symptoms". The word 'help' itself only means to aid or to assist; thus, it cannot be interpreted that the product will stop or eliminate the cold.

The use of up to claim is often found in malls or supermarkets in phrases like "discount up to 70\%", for example. The phrase "up to" suggests a wide range from 1 to $70 \%$. Therefore, it is possible that the product turns out to be discounted only for 20 or $30 \%$, and only a few products get the real $70 \%$ discount (Lutz, 1989, p. 85).

According to Lutz (1989, p. 95), "unfinished words abound in advertising because they appear to promise so much." When a cold remedy slogan says "nobody reduces fever faster", it is actually not clear yet. The word 'faster' suggests a comparison and 
therefore, it requires some more words to finish the comparison. However, the phrase is intentionally left unfinished as it is up to the customers to finish it, which is a very clever strategy.

\section{Results and Discussion}

The 103 respondents are students and alumni of the English Department and their ages vary from 16 to $>30$ years old. Besides, the respondents are heterogeneous in gender; there are male and female respondents. The distribution of the age and gender of the respondents can be seen in the following charts:

\section{Figure 2. Respondents' Ages}

Usia:

103 responses

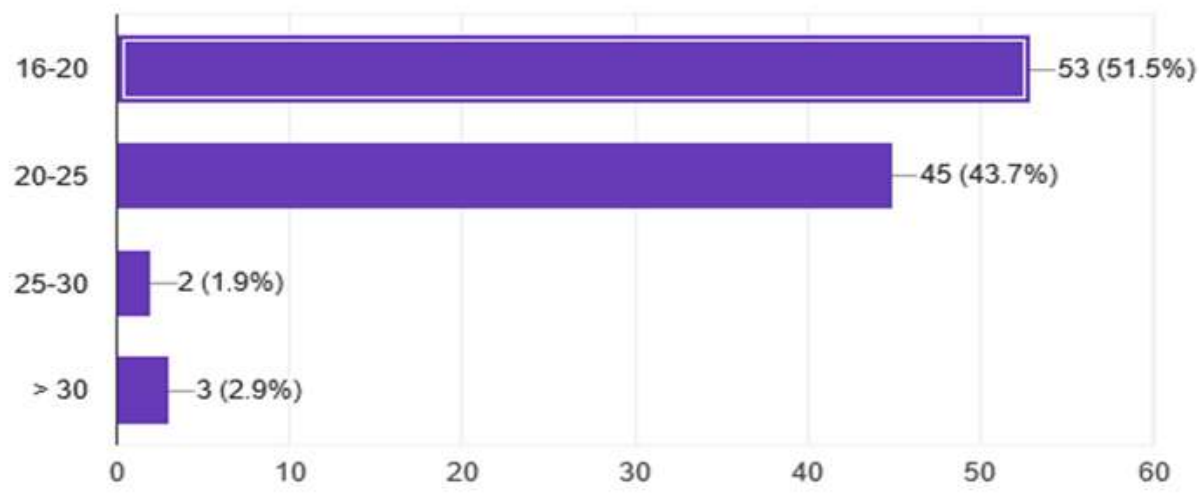

Figure 3. Respondents' Gender

\section{Jenis Kelamin}

103 responses

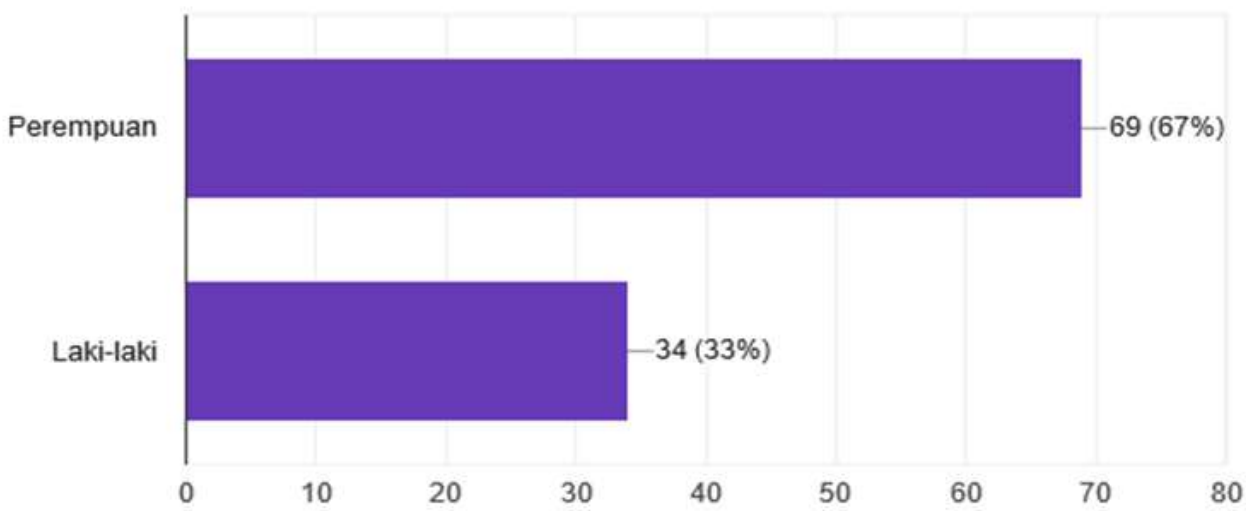

It is clear from the two charts above that the most dominant group is respondents of $16-20$ years old and female.
Related to the level of awareness of the visual aspect in advertisement 1 , the result of the questionnaire shows that most of the 
respondents think it is either interesting or very interesting: $62.1 \%$ in advertisement 1 , $64.1 \%$ in advertisement 2 , and $31 \%$ in advertisement 3 , as can be seen in the following charts in Figures 4, 5, and 6.

\section{Figure 4. Awareness of the Visual Aspect in Advertisement}

\section{Menurut saya tampilan visual iklan ini:}

\section{3 responses}

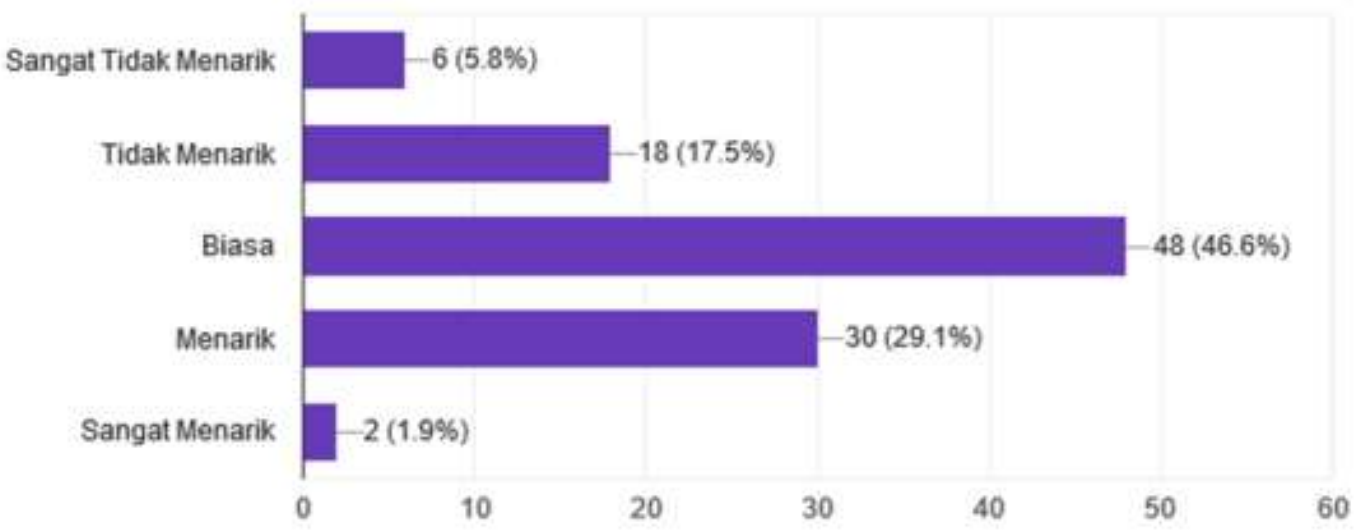

Figure 5. Awareness of the Visual Aspect in Advertisement 2

\section{Menurut saya tampilan visual iklan ini :}

\section{3 responses}

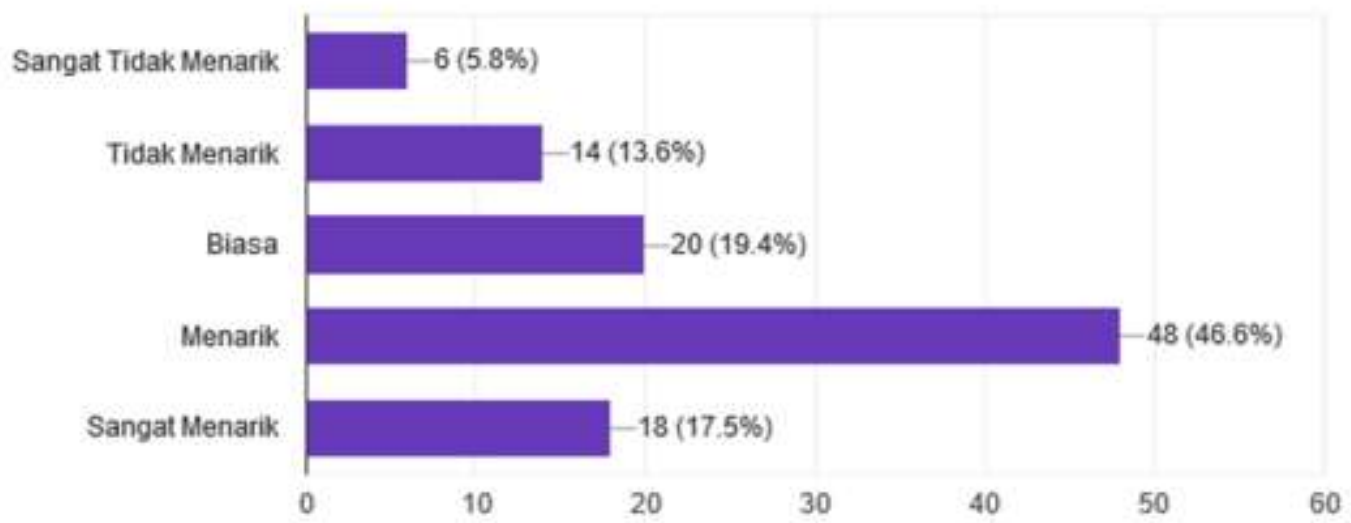


Figure 6. Awareness of the Visual Aspect in Advertisement 3

\title{
3. Menurut saya tampilan visual iklan ini:
}

\author{
103 responses
}

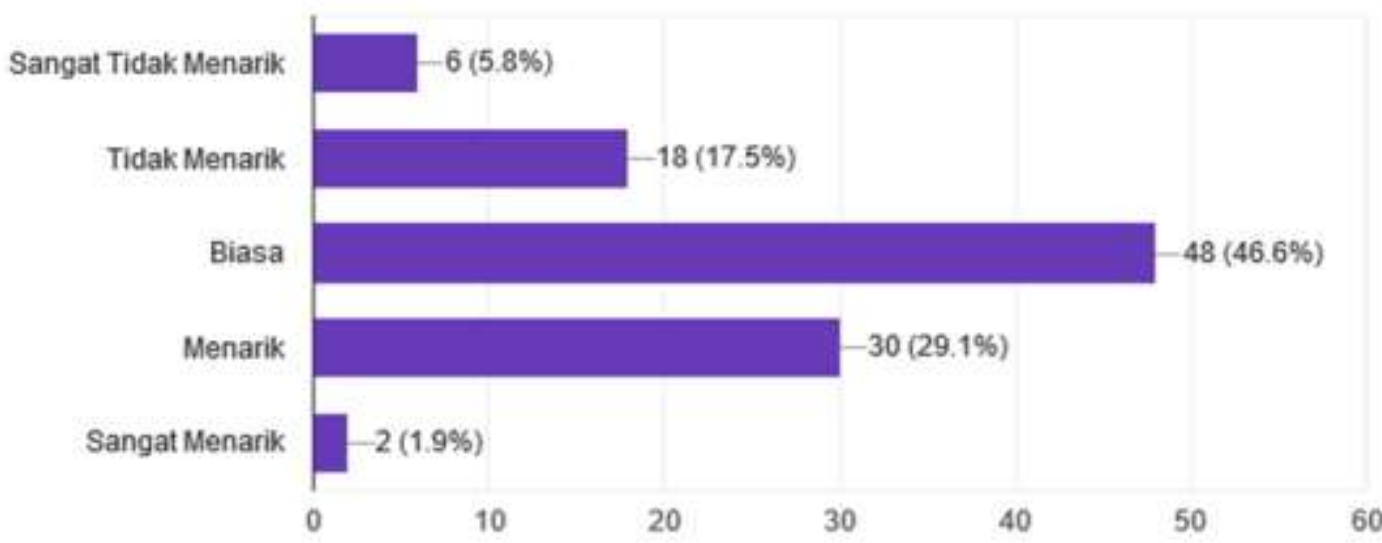

The next questions posed in the questionnaire are related to the respondents' level of awareness of the textual aspect or the slogans in the three advertisements. There are $47.6 \%$ who think that the slogan in advertisement 1 ("The best coffee for the best you") is either interesting or very interesting;

$47.5 \%$ for advertisement slogan 2 ("Butts are gross") and $45.6 \%$ for advertisement slogan 3 ("Butter taste better health"). The result is clear in the following charts in Figures 7, 8, and 9 below.

Figure 7. Awareness of the Textual Aspect in Advertisement 1

\section{Menurut saya slogan iklan pertanyaan nomor 1: "The best coffee for the best you" \\ 103 responses}

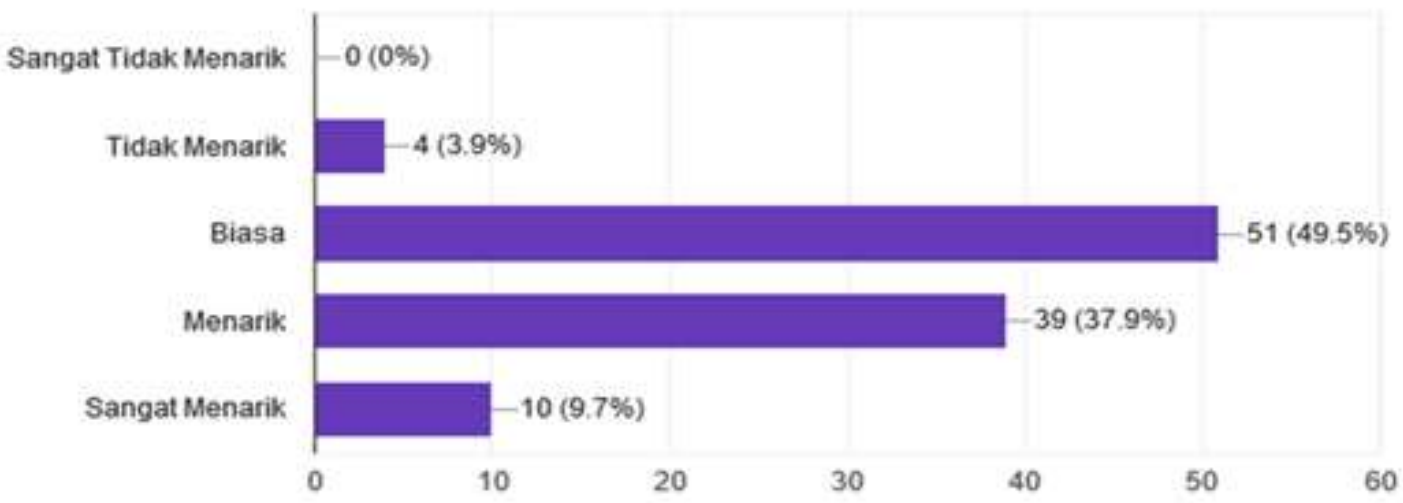


Figure 8. Awareness of the Textual Aspect in Advertisement 2

\section{Menurut saya slogan iklan pertanyaan nomor 2: "Butts are gross" 103 responses}

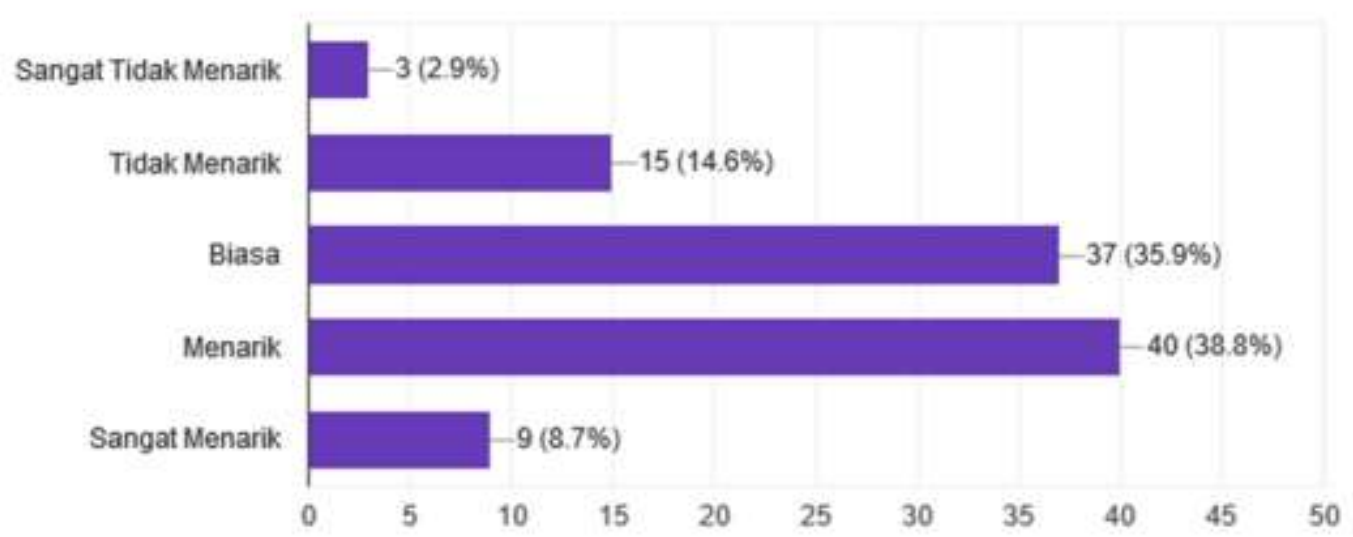

Figure 9. Awareness of the Textual Aspect in Advertisement 3

\section{Menurut saya slogan iklan pertanyaan nomor 3: "Butter taste better health" \\ 103 responses}

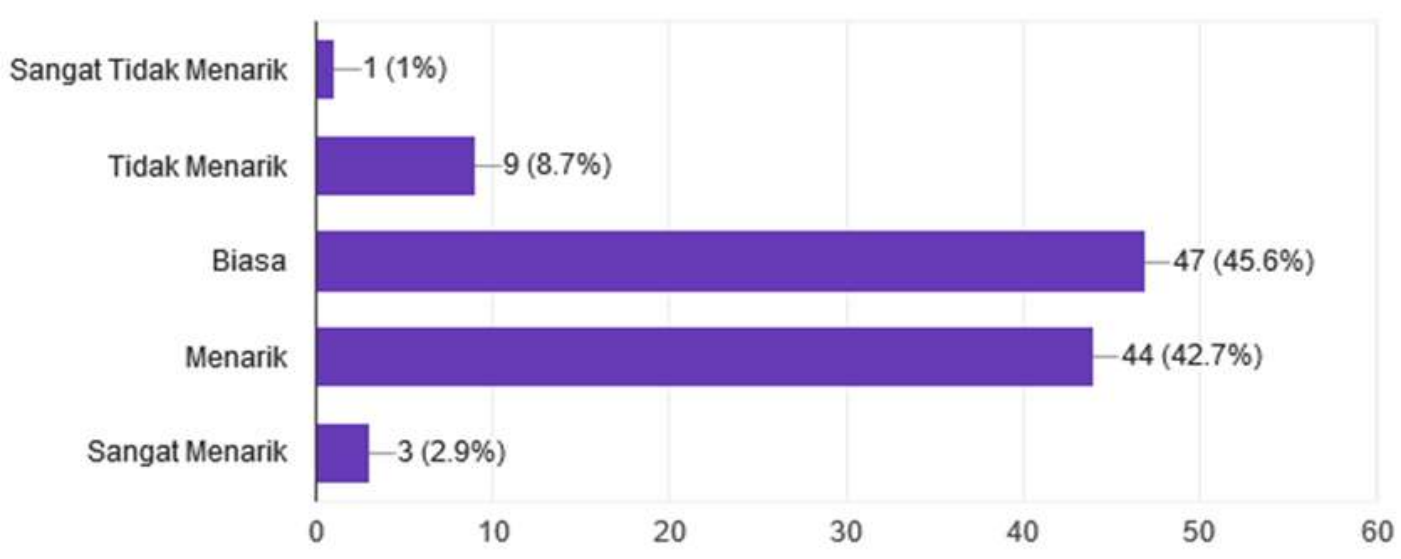

Comparing the level of visual awareness and textual or slogan awareness, the result shows the following:

Table 1. Comparison of awareness level of the visual and textual aspects

\begin{tabular}{|c|c|c|}
\hline Advertisement & Visual & Textual \\
\hline 1 & $62.1 \%$ & $47.9 \%$ \\
\hline 2 & $64.1 \%$ & $47.5 \%$ \\
\hline 3 & $31 \%$ & $45.6 \%$ \\
\hline
\end{tabular}

This means that most of the respondents tend to be more aware of the distinctive things visually than textually.

Furthermore, focusing more on the textual aspect of the advertisements, the research is also done to find out the correlation between the awareness and appreciation of the textual aspect. When the respondents claim that the textual aspect in a certain advertisement slogan is interesting or very interesting, they are required to identify which linguistic 
feature(s) is distinctive as to make the slogan interesting.

The slogan of the first advertisement, "The best coffee for the best you", contains at least three rhetorical figures using the repetition operation. The first is word repetition of the word 'best'; the second is phrase structure repetition 'the best coffee' and 'the best you'. Besides, when read, each of the two noun phrases contains two stresses, on the word 'best', the first syllable of 'coffee', the words 'best', and 'you'. This naturally produces great rhythm.

The statistical tool to test the equation in this research is logistic regression, which is used because the dependent variable of the equation is a dummy variable. The model equation is $Y=a+b_{1} \cdot X_{1}+b_{2} \cdot X_{2}$, in which $Y$ is the appreciation level of the respondents who see the advertisement; $X_{1}$ is the visual awareness and $X_{2}$ is the slogan awareness.

Concerning advertisement 1, H01 and Ha1 are as follows: In H01, there is no correlation between visual awareness and slogan awareness of advertisement 1 and the level of appreciation from the people who see the advertisement; In Ha1, there is a correlation between visual awareness and slogan awareness of advertisement 1 and the level of appreciation from the people who see the advertisement.

\section{Model Summary}

\begin{tabular}{|c|c|c|c|}
\hline Step & $\begin{array}{c}\text {-2 Log } \\
\text { likelihood }\end{array}$ & $\begin{array}{c}\text { Cox \& Snell R } \\
\text { Square }\end{array}$ & $\begin{array}{c}\text { Nagelkerke R } \\
\text { Square }\end{array}$ \\
\hline 1 & $68.287^{a}$ & .151 & .266 \\
\hline
\end{tabular}

$a=$ Estimation terminated at iteration number 6 because parameter estimates changed by less than .001.

The Nagelkerke $\mathrm{R}$ Square is 0.266 signalling the $26.6 \%$ variabilities of the dependent variable can be explained by the variabilities of the independent variable.

\section{Hosmer and Lemeshow Test}

\begin{tabular}{|c|c|c|c|}
\hline Step & Chi-square & df & Sig. \\
\hline 1 & 6.985 & 5 & .222 \\
\hline
\end{tabular}

The value of Hosmer and Lemeshow is 6.985 and significant at 0.222 is above the alpha value of $1 \%$, which signifies that the model is fit and acceptable.

\section{Classification Table}

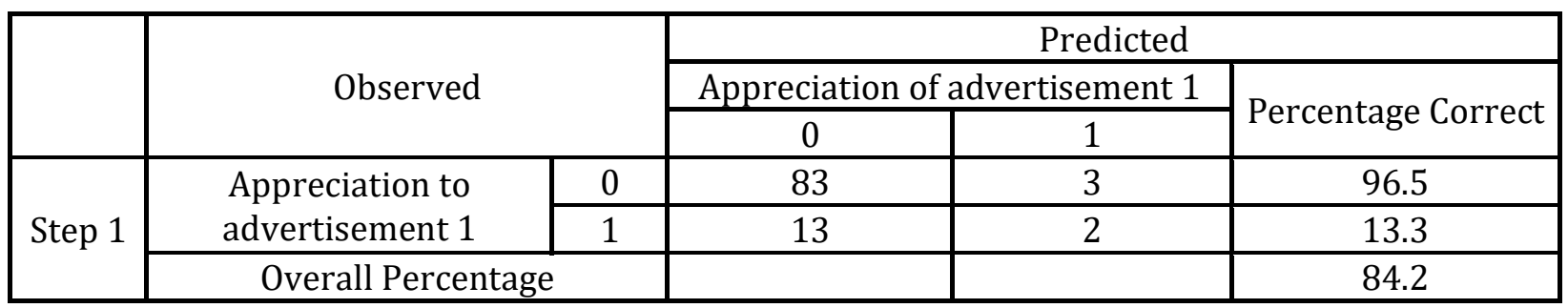

$a=$ The cut value is .500

The figures in the classification table identify that overall the accuracy of classification is $84.2 \%$.

\section{Variables in the Equation}

\begin{tabular}{|c|c|c|c|c|c|c|c|}
\hline \multicolumn{2}{|c|}{} & B & S.E. & Wald & df & Sig. & Exp(B) \\
\hline \multirow{3}{*}{ Step 1 } & Visual_A1 & .836 & .474 & 3.113 & 1 & .078 & 2.307 \\
\cline { 2 - 8 } & Slogan_A1 & 1.248 & .477 & 6.838 & 1 & .009 & 3.484 \\
\cline { 2 - 8 } & Constant & -9.759 & 2.452 & 15.843 & 1 & .000 & .000 \\
\hline
\end{tabular}

Based on the table of variables in the equation it is clear that at the alpha value of $10 \%$ there is a significant correlation between the visual awareness and slogan awareness of the first advertisement and the appreciation level of the people who see the advertisement. 
It can be interpreted that people who are aware of the distinctive aspects of advertisement 1 visually and textually are also able to appreaciate the outstanding linguistic features of the slogan.

In the second advertisement, the slogan "Butts are gross" is linguistically speaking very interesting as it contains several rhetorical figures. The three words in the slogans are one-syllabled words so that the beats are regular and it creates good rhythm when read. Thus, this belongs to the repetition operation. Besides, the word 'butt' is in fact homonymous, as it has double meanings. It can refer to the slang word for one's bottom or the part of a cigarette that is left after being smoked. The humour will be built when this word is put in the context of the advertisement. This word obviously creates a pun or wordplay and this belongs to the destabilization operation.

H02 and Ha2 of advertisement 2 are as follows: In $\mathrm{H} 02$ there is no correlation between visual awareness and slogan awareness of advertisement 2 and the level of appreciation from the people who see the advertisement; In $\mathrm{Ha} 2$ there is a correlation between visual awareness and slogan awareness of advertisement 2 and the level of appreciation from the people who see the advertisement.

\section{Model Summary}

\begin{tabular}{|c|c|c|c|}
\hline Step & $\begin{array}{c}-2 \text { Log } \\
\text { likelihood }\end{array}$ & $\begin{array}{c}\text { Cox \& Snell R } \\
\text { Square }\end{array}$ & $\begin{array}{c}\text { Nagelkerke R } \\
\text { Square }\end{array}$ \\
\hline 1 & $79.875^{\mathrm{a}}$ & .309 & .451 \\
\hline
\end{tabular}

$a=$ Estimation terminated at iteration number 6 because parameter estimates changed by less than .001

The Nagelkerke $\mathrm{R}$ Square is 0.451 signalling the $45.1 \%$ variabilities of the dependent variable can be explained by the variabilities of the independent variable.

\section{Hosmer and Lemeshow Test}

\begin{tabular}{|c|c|c|c|}
\hline Step & Chi-square & df & Sig. \\
\hline 1 & 5.510 & 5 & .357 \\
\hline
\end{tabular}

The value of Hosmer and Lemeshow is 5.510 and significant at 0.357 is above the alpha value of $1 \%$, which signifies that the model is fit and acceptable.

\section{Classification Table ${ }^{a}$}

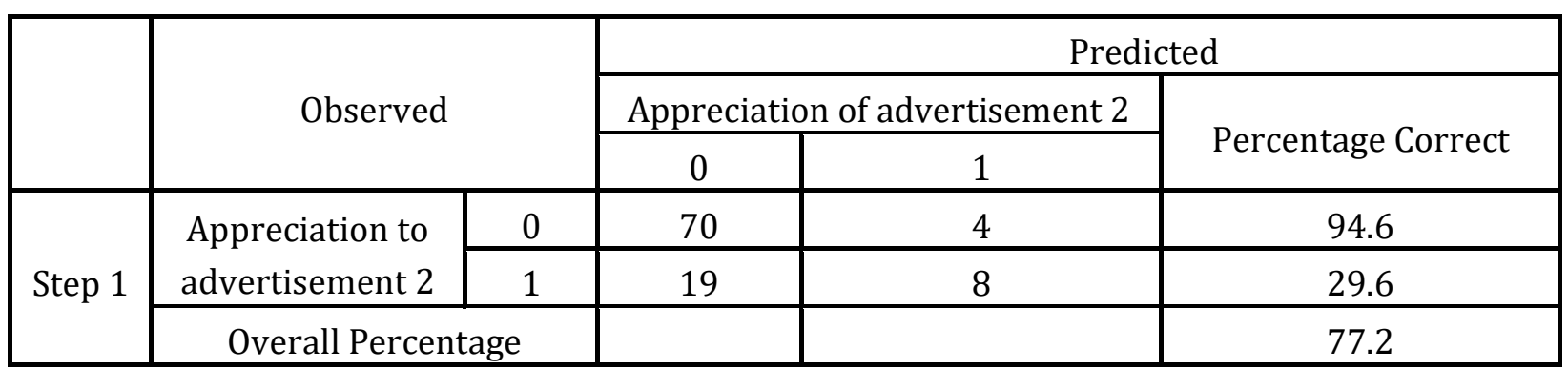

$a=$ The cut value is .500

The figures in the classification table identify that overall the accuracy of classification is $77.2 \%$.

Variables in the Equation

\begin{tabular}{|c|c|c|c|c|c|c|c|}
\hline \multicolumn{2}{|c|}{} & B & S.E. & Wald & df & Sig. & Exp(B) \\
\hline \multirow{3}{*}{ Step 1 $^{a}$} & Visual_A2 & .414 & .448 & .853 & 1 & .356 & 1.513 \\
\cline { 2 - 8 } & Slogan_A2 & 2.034 & .568 & 12.823 & 1 & .000 & 7.643 \\
\cline { 2 - 8 } & Constant & -9.996 & 2.304 & 18.819 & 1 & .000 & .000 \\
\hline
\end{tabular}

$a=$ Variable(s) entered on step 1: Visual_A2, Slogan_A2.

Based on the table of variables in the equation above, it can be seen that at the alpha value of $10 \%$ there is no significant correlation between the visual awareness and the textual awareness level of the people who see the advertisement. Hence, people who think that 
the visual aspect of the advertisement is interesting do not necessarily think the same of the textual aspect of the advertisement. However, there is a significant correlation between the slogan awareness and the appreciation level. Thus, in advertisement 2 , it can be said that people who are aware that the textual aspect of the advertisement is interesting manage to identify what outstanding linguistic features are used in the slogan.

The third advertisement slogan "Butter taste better health" is also interesting in the fact that it abounds in the types of special linguistic features. In the repetition operation, the use of the minimal pairs 'butter' and 'better' will definitely attract the customers' attention as the two words sound very much alike. These two words also show the repetition of the consonant $/ \mathrm{b} /$ at the beginning the words, which is an alliteration, and the repetition of the consonant $/ t /$ in the middle position, which is called a consonance. Besides, there is also a repetitive noun phrase construction in the phrases 'butter taste' and 'better health'. These two noun phrases contain three syllables each so that when the whole slogan is read, good rhythm is produced.

Besides the rhetorical figures in the repetition operation, the slogan also contains one form of doublespeak, namely the unfinished word. The comparative adjective 'better' in the phrase 'better heatlh' leaves an open interpretation, as the slogan does not finish the comparison of what this product will cause better health than.

$\mathrm{H} 03$ and Ha3 of advertisement 3 are as follows: In H03 there is no correlation between visual awareness and slogan awareness of advertisement 3 and the level of appreciation from the people who see the advertisement; In Ha3: there is a correlation between visual awareness and slogan awareness of advertisement 3 and the level of appreciation from the people who see the advertisement.

\section{Model Summary}

\begin{tabular}{|c|c|c|c|}
\hline Step & $\begin{array}{c}\text {-2 Log } \\
\text { likelihood }\end{array}$ & $\begin{array}{c}\text { Cox \& Snell R } \\
\text { Square }\end{array}$ & $\begin{array}{c}\text { Nagelkerke R } \\
\text { Square }\end{array}$ \\
\hline 1 & $81.914^{\mathrm{a}}$ & .230 & .350 \\
\hline
\end{tabular}

$a=$ Estimation terminated at iteration umber 6 because parameter estimates changed by less than .001.

The Nagelkerke R Square is 0.35 signalling the $35 \%$ variabilities of the dependent variable can be explained by the variabilities of the independent variable.

\section{Hosmer and Lemeshow Test}

\begin{tabular}{|c|c|c|c|}
\hline Step & Chi-square & df & Sig. \\
\hline 1 & 11.726 & 5 & .039 \\
\hline
\end{tabular}

The value of Hosmer and Lemeshow is 11.726 and significant at 0.039 is above the alpha value of $1 \%$, which signifies that the model is fit and acceptable.

\section{Classification Table}

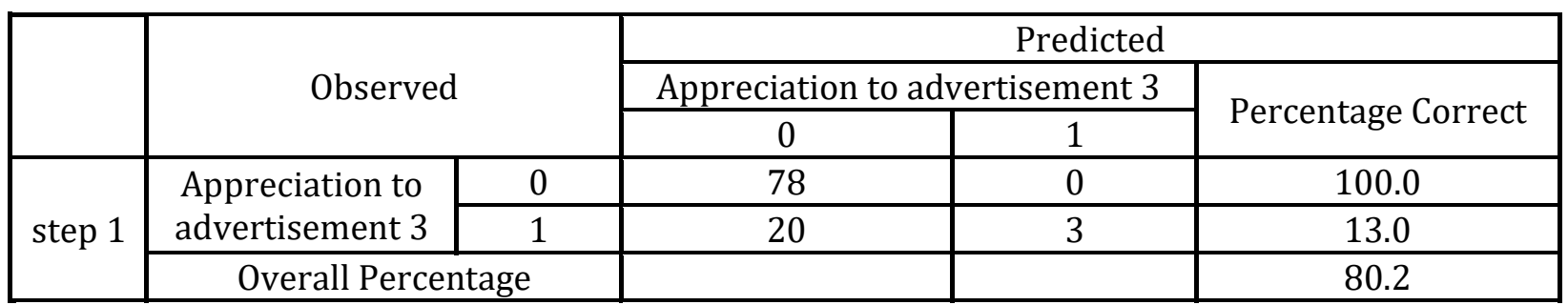

$a=$ the cut value is .500

The figures in the classification table identify that overall the accuracy of classification is $80.2 \%$. 
Variables in the Equation

\begin{tabular}{|c|c|c|c|c|c|c|c|}
\hline \multicolumn{2}{|c|}{} & B & S.E. & Wald & df & Sig. & Exp(B) \\
\hline \multirow{3}{*}{ Step 1a } & Visual_A3 & -.217 & .343 & .402 & 1 & .526 & .805 \\
\cline { 2 - 8 } & Slogan_A3 & 2.539 & .651 & 15.199 & 1 & .000 & 12.663 \\
\cline { 2 - 8 } & Constant & -9.771 & 2.491 & 15.393 & 1 & .000 & .000 \\
\hline
\end{tabular}

$a=$ Variable(s) entered on step 1: Visual_A3, Slogan_A3.

Based on the table of variables in the equation above, it can be seen that at the alpha value of $10 \%$ there is no significant correlation between the visual awareness and the textual awareness level of the people who see the advertisement. Therefore, those finding the visual aspect of the advertisement interesting do not necessarily find the textual aspect interesting as well. However, there is a significant correlation between the slogan awareness and the appreciation level. Thus, in advertisement 3 , it can be said that people who are aware that the textual aspect of the advertisement is interesting manage to identify what outstanding linguistic features are used in the slogan.

\section{Conclusion}

It is interesting to notice that among all the answers concerning the linguistic features used in the slogans, most respondents can identify the repetition operation, whether it is the sound or word or phrase structure repetition, and some can identify the pun in advertisement 2. Quite surprisingly, no one can identify the use of doublespeak, in this case the unfinished word. This confirms the notion that repetitive forms are the most obvious features as well as the least complex operation; therefore, people can easily detect them. The pun in the second advertisement, on the other hand, can be identified by fewer people compared to the repetitive forms. Related to the rhetorical operations, it is again confirmed that a pun, which belongs to the destabilization operation, is not easily identified as it involves a more complex operation. It is also worth noting down that the use of doublespeak is not easily detected, which suggests that this tool may be the most effective for advertisers to use since the misleading intention will not be easily detected by customers.

This research has several limitations, one of which regards the number of advertisements analyzed. With only three advertisements, definitely the findings of the research cannot be generalized. It is suggested that future research analyze more advertisements. It is also suggested that the advertisements analyzed can be more homogenous, for example cosmetic advertisements or car advertisements only. In this way, the findings are expected to be more focused and specialized, which will result in some more accurate findings.

Another limitation regards the scope of the population of this research, which is restricted to students and alumni of the English Department of a particular university. In the next research, a more diverse population can lead to a more accurate and generalized finding.

The next research can also be made wider by collaborating with experts in graphic design. In this way, the research not only covers the textual aspect, but can also cover the visual aspect as well, considering that printed advertisements most probably contain both aspects.

\section{References}

Bizzoca, Angela. (2017). The Incidence of Rhetorical Figures in British Print Advertisement. Retrieved from: https:// www.academia.edu/37117929/The_Inci dence_of_Rhetorical_Figures_in_British_P rint_Advertisement

Butter taste better health. (n.d.). Retrieved from https://goo.gl/images/x4ALk5

Butts are gross. (n.d.). Retrieved from https://goo.gl/images/zbRYxR 
Bly, Robert. (2005). The Copywriter's Handbook: A Step-by-Step Guide to Writing Copy that Sells ( $3^{\text {rd }}$ ed.). New York: Henry Holt and Company.

Kreidler, Charles. (1998). Introducing English Semantics. London: Routledge.

Leech, Geoffrey and Michael Short. (1981). Style in Fiction. New York: Longman Group Limited.

Leigh, James. (2013). The Use of Figures of Speech in Print Ad Headlines. Journal of Advertising, Vol. 23, No. 2, 17-33. Retrieved from: https://www. tandfonline.com/doi/abs/10.1080/0091 3367.1994.10673439

McQuarrie, Edward. \& David Mick. (1996). Figures of Rhetoric in Advertising Language. The Journal of Consumer Research, Vol. 22, No. 4, 424-438. Retrieved from http://www.jstor.org/

Merriam-Webster Dictionary. (n.d.). Retrieved from https://www.merriam-webster.com

Partington, Alan. (2009). A linguistic account of wordplay: The lexical grammar of punning. Journal of Pragmatics. Vol. 42, no. 9, 1794-1809.

Starbucks commercial propaganda site. (n.d.). Retrieved from https://goo.gl/images/ ubMtel

Ushurova, Shachida. Translate the Pun, Sacrifice the Fun: A Comparative Case Study of the Dutch Subtitled Wordplay in an Episode of The Persuaders! (n.d.). Retrieved from http://www.ethesis.net/ Wordplay/Wordplay>

Verdonk, Peter. (2002). Stylistics. Oxford:

Oxford University Press.
Wales, Katie. (1994). A Dictionary of Stylistics. Essex: Longman Group Limited.

What is Quantitative Research? (n.d.). Retrieved from https://www.sisinter national.com/what-is-quantitativeresearch/ 